Issue 1/2018

\title{
THE IMPACT OF THE ONLINE ENVIRONMENT ON TOURISM
}

\author{
Bogdan SOFRONOV ${ }^{1}$ \\ ${ }^{1}$ University Politehnica of Bucharest, Splaiul Independenței 313, Bucharest, \\ 060042, Romania, Email: bogdansofronov@yahoo.com
}

\begin{abstract}
The online tourism is part of e-commerce and unites some of the fastest growing technologies, such as communications and information technology, the hospitality industry, and strategic management / marketing / planning.

Online tourism activities involve tour operators, travel agencies and other entities with tourism-related interests in the virtual space through a dedicated portal. The phenomenon itself has implications for the tourist services consumer.

The Internet has revolutionized the travel industry both as a source of information and as a sales channel. Online marketing, photographs, and consumer reviews are bringing destinations and attractions to the screens of potential travellers around the world. The ease with which a customer can review and compare travel options opens up new markets for both large and small businesses and the ability to confirm prices and purchase services online benefits travellers and businesses alike.
\end{abstract}

Keywords: online tourism; e-commerce; tourism; travel industry; international tourism.

JEL Classification: Z30, Z32

\section{Introduction}

The online tourism plays a vital and growing role in the travel sector. In fact, the online content is now a primary source of travel information, exceeding all other forms of traditional media and marketing. Travel businesses connect with consumers through online marketing, social media, travel apps, search functionality, and booking platforms. These diverse information sources and sales channels increasingly drive the tourism sector. [The Impact of Online Content on European Tourism, 2013]

However, even though tourism demand is increasingly shifting to an online environment, and culture is an important motivating factor, a relatively low proportion 


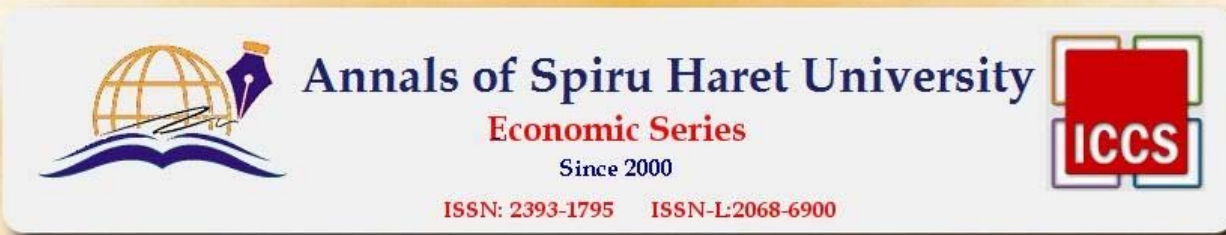

\section{Issue 1/2018}

of enterprises in Spain, Italy, and Greece are using e-commerce to connect to potential customers. Such an imbalance presents a significant opportunity to increase sales with more widespread industry adoption of Internet sales and marketing platforms. [The Impact of Online Content on European Tourism, 2013]

The online tourism represents a significant business, with online content supporting $10 \%, 26 \%$, and $43 \%$ of all tourist arrivals in Greece, Italy, and Spain. The EU average is $49 \%$, including research and booking. This leaves significant upside potential for the tourism industry in these countries to more fully embrace an online presence. [The Impact of Online Content on European Tourism, 2013]

Online tourism provides benefits to smaller and independent establishments, as well as well-known brands. By extension, increased online content also benefits the cultural tourism segment, which includes many small and medium-sized enterprises, allowing tourists to experience more niche cultural activities. [The Impact of Online Content on European Tourism, 2013]

The Internet has become a highly trusted source of information and the overall impact of online content includes a large effect from research in addition to the online sales. The total impact of travel organized online includes the impact of online tourism sales, as well as trips, which have been researched online. [The Impact of Online Content on European Tourism, 2017]

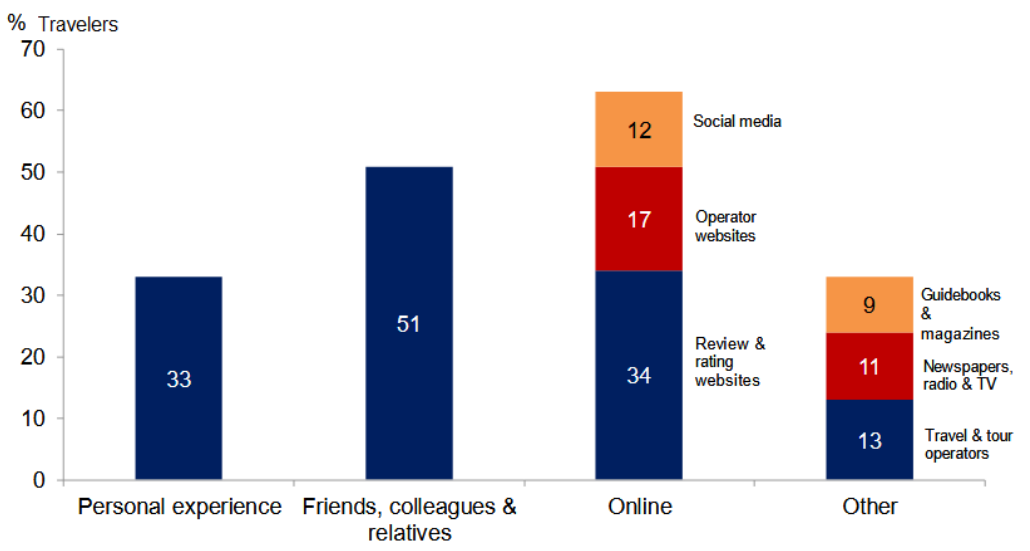

Figure no. 1. Most important sources of travel information

Source: http://www.oxfordeconomics.com/recent-releases/the-impact-of-online-content-oneuropean-tourism 


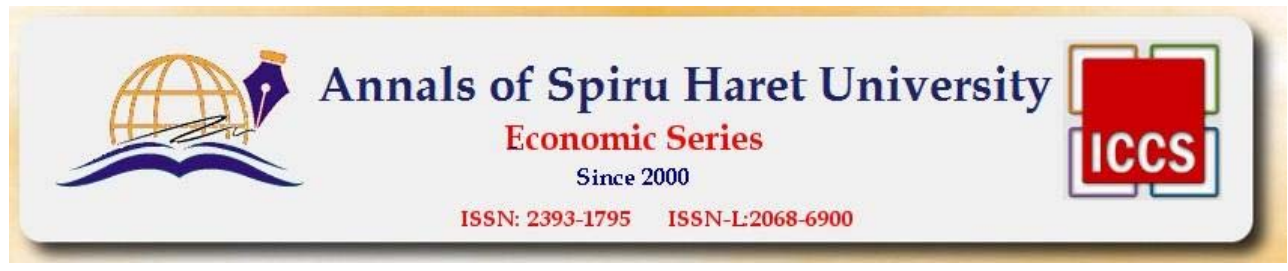

Issue 1/2018

\section{Literature review}

My research paper entitled The impact of the online environment on tourism is written after I have documented based on the following published articles:

1. "E-tourism: Concept and Evolution" written by Iulian Condratov published in EcoForum Journal.

2. "The Future eTourism Intermediaries" written by Dimitrios Buhalis and Maria Cristina Licata published in the International Journal of Tourism Management.

3. "The Impact of Using the Internet in Promoting Romanian Industry" written by Carmen Adina Pastiu published in Annals of Spiru Haret University. Economic Series.

\section{The online tourism in the world}

The online tourism is growing fast due to the accessibility of information related to destinations, attractions and sights, maps, impressions and opinions of other tourists who visited these places, creating the conditions for choosing a holiday and a good vacation. The many offers of accommodation, special offers, last minute, early booking, circuits, cruises, hotels and flights present in the online environment and the ease of accessing them from home or office facilitates the purchase of tourist packages at the same or lower rates like those of the agency.

The tourism industry in Greece would benefit from a long-run increase in demand of up to $20 \%$ if action were taken to increase online activity to match that of leading EU countries. [The Impact of Online Content on European Tourism, 2013]

Taking wider benefits into account, including the supply-chain, this would increase Greece GDP by 3\%, and would generate over 100,000 new jobs. [The Impact of Online Content on European Tourism, 2013]

Italy would realise an incremental benefit to tourism demand of around $10 \%$ and a boost to whole economy GDP and employment of around 1\%. Given the size of the economy, this would translate into around 250,000 new jobs. [The Impact of Online Content on European Tourism, 2013]

Spain does not lag as far as the others in terms of online penetration but the opportunities are still significant. Tourism demand would increase $3 \%$ with a $0.5 \%$ boost to total GDP. This would still translate into a notable employment benefit with over 50,000 new jobs. [The Impact of Online Content on European Tourism, 2013]

Increased cultural online content alone could have a long-run benefit to whole economy GDP of around 1.5\% in Greece, generating 50,000 new jobs. The benefits would be smaller in Italy and Spain, but still significant, pushing GDP up $0.3 \%$ in 

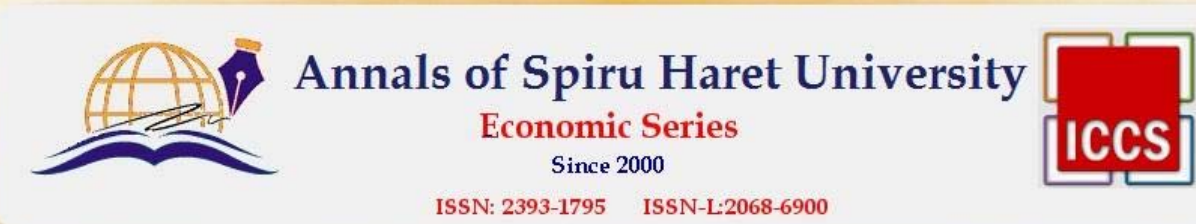

Issue 1/2018

Italy and $0.2 \%$ in Spain: equivalent to around 75,000 and 20,000 new jobs. [The Impact of Online Content on European Tourism, 2013]

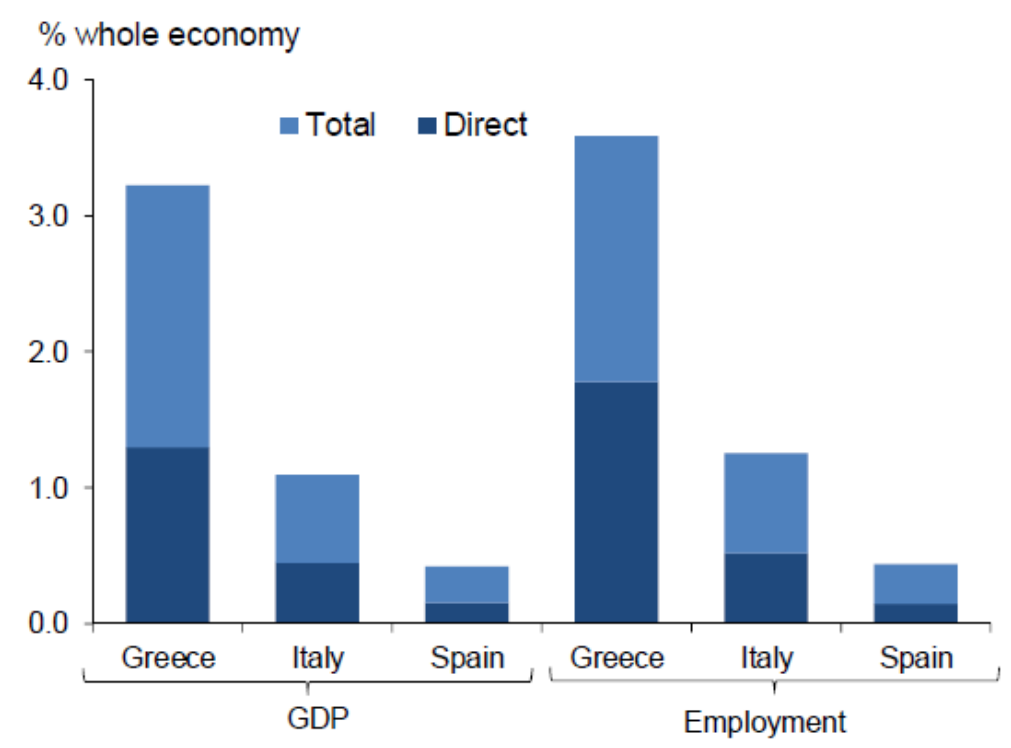

Figure no. 2. Incremental online tourism opportunity

Source: http://www.oxfordeconomics.com/my-oxford/projects/246666

In order to achieve this opportunity, the tourism industry in Greece, Italy, and Spain would need to take at least some of the following steps [The Impact of Online Content on European Tourism, 2013]:

- businesses must further develop their online presence (in multiple languages) as a primary marketing and booking channel. This should span various platforms (website, travel apps, search, sales portals, travel reviews, travel guides) and include ever deepening content. Development of content spanning both established and smaller, niche enterprises will generate further impacts;

- develop online content for cultural tourism. Given the significant role that culture plays in tourism, the Internet presents a large opportunity to motivate travel by exposing cultural assets to consumers;

- government agencies can work with the private sector to provide complementary destination and cultural online content; 

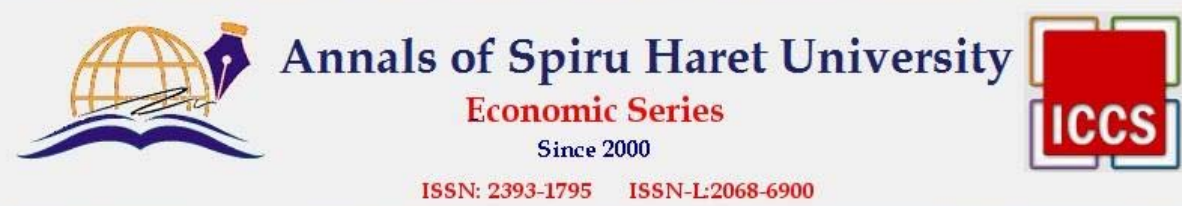

Issue 1/2018

- engage with social media and encourage feedback from customers. This will allow businesses to build relationships with their customers, as well as improve service offerings over time.

Internet access has helped to fuel global tourism growth by contributing to global connectivity. Increased provision of online information and easier access means that the connection between businesses and potential travellers is stronger than ever before. This element of connectivity is an important factor driving the continued strong growth in global tourism demand. [The Impact of Online Content on European Tourism, 2017]

Social media has become an important tool for the younger generation and, over time, the current societal and generational differences in attitudes to social media will fade. As well as optimising online content for mobile browsing, businesses need to embrace social media to take full advantage of the benefits of the Internet. [The Impact of Online Content on European Tourism, 2017]

In terms of e-business management, initiators need to constantly review strategies, techniques and tools in the light of new technologies.

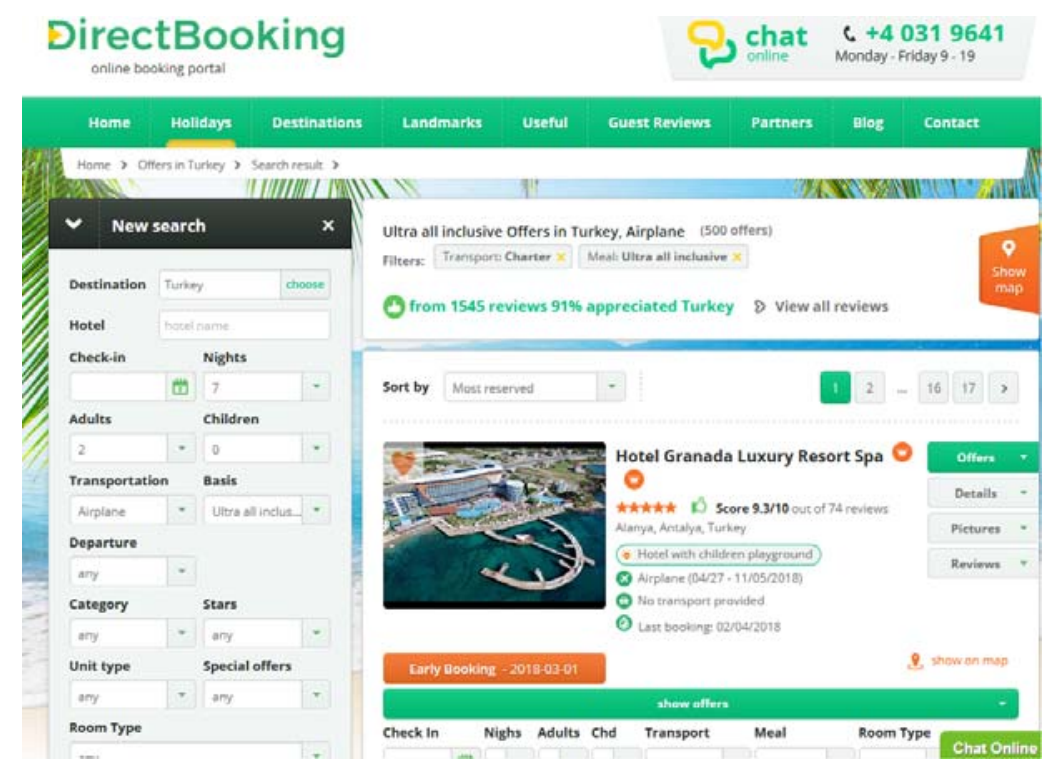

Figure no. 3. Example of electronic information method using www.directbooking.ro

Source: https://www.directbooking.ro 
Issue 1/2018

\section{The implications of online tourism for tourists}

The online tourism involves the following issues for end-users: e-information, e-reservation and electronic payment.

The e-information stage involves providing information in specialized portals, electronic brochures, audio tour guides, photo albums, real-time images or video clips, and even travel journals via blogs or virtual virtual communities, such as Virtual Tourist, and why not, guides through virtual cities.

Online reservations are mostly used in hotel, air travel and car rental services.

Online reservation services as information society services must comply with legal requirements stemming from normative acts that refer to Internet services in general and to e-commerce and the conclusion of distance contracts in particular.

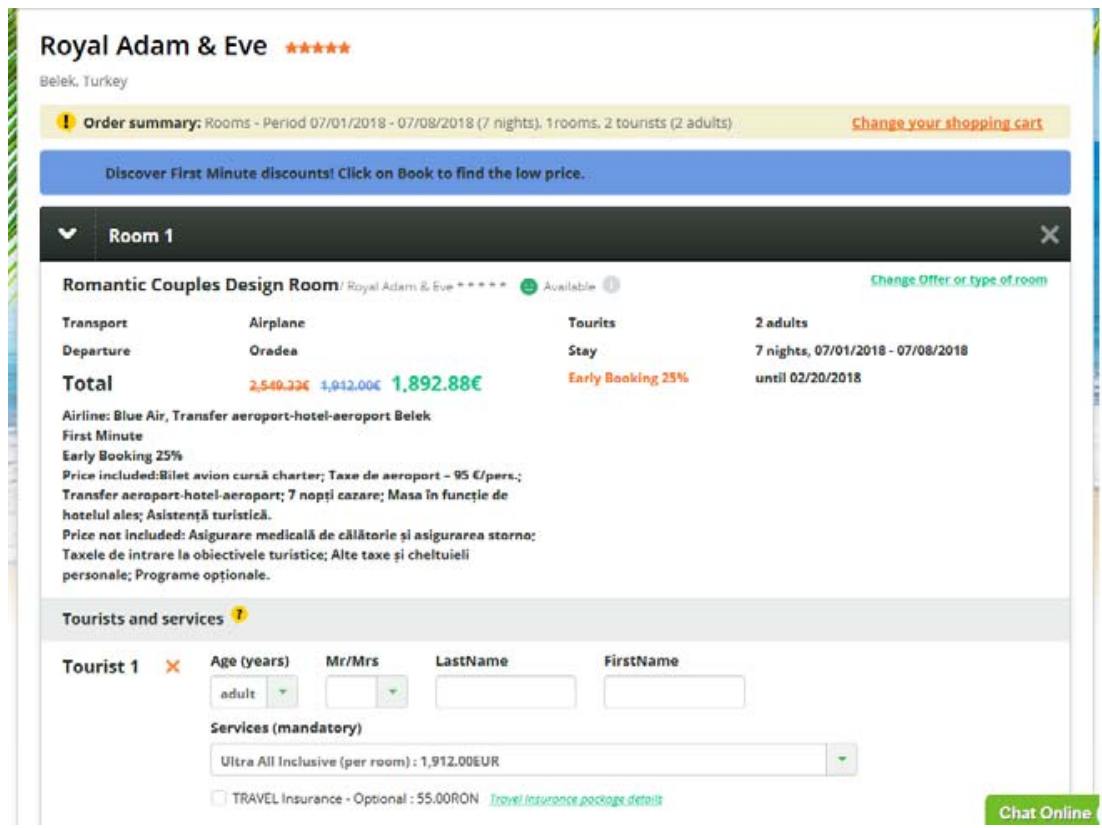

Figure no. 4. Example of electronic solving method using www.directbooking.ro Source: https://www.directbooking.ro 

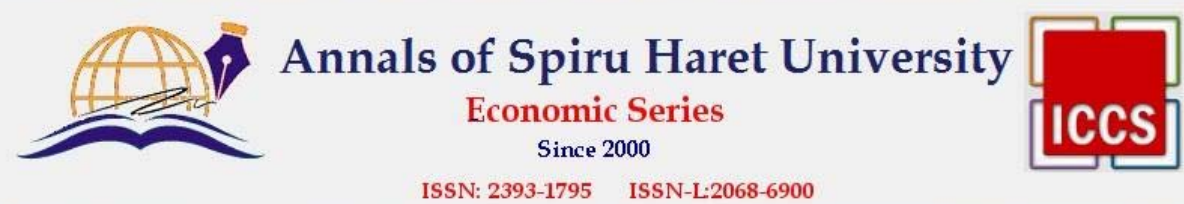

Issue 1/2018

Consumers can use credit cards, electronic checks, and digital money when payments amount to just a few cents. Many of the electronic payment systems on the Internet are the equivalent of electronic systems used every day, such as credit cards, checks, etc. Even the digital money, meant to represent the currency, is available.

The card, debit or credit card, may fulfil under certain conditions other functions, such as the coverage of risks, as well as an insurance policy or assistance in certain situations.

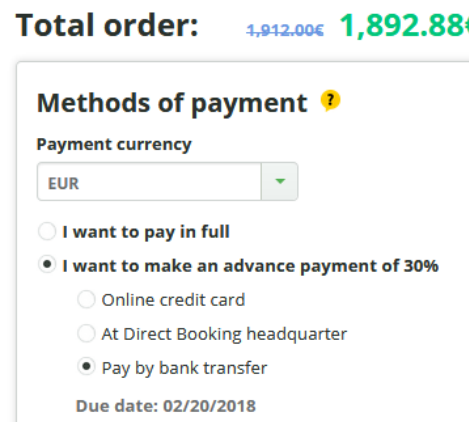

Figure no. 5. Example of electronic payment method using www.directbooking.ro

Source: https://www.directbooking.ro

E-business in the field of tourism services automates the order process, increases the number of outlets, and thus improves efficiency, reduces costs and highlights competitiveness. It also allows agencies and tour operators to analyze potential customers and manage their resources properly.

The information systems in online tourism, as an integrated part of the information system at the company level, include both manual and automated phases of information collection and recording, information analysis and information processing.

There are two categories of computer systems that serve tourist services: frontoffice computer systems, and computer systems used for tourist bookings using the Internet.

The front-office computer systems process information and provide reports in written or visual form. They are used both in medium and large tourist accommodation structures, but also in travel agencies. These systems are designed for tourists' registration, room management and management, for the marketing of tourist products, 


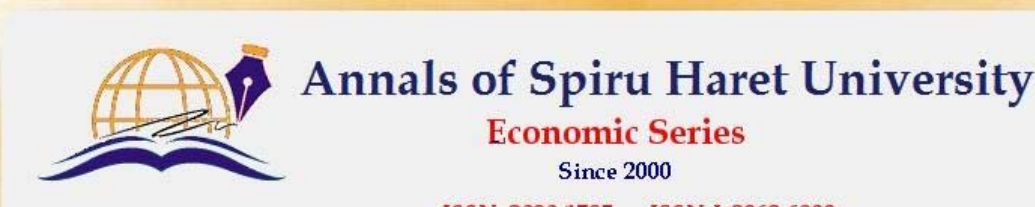

ISSN: 2393-1795 ISSN-L-2068-6900

\section{Issue 1/2018}

or for cash registers. Two such systems that include all of the above activities are Medallion PMS and Epitome PMS, applications that work with complex service packages such as: free time organization, profit optimization, invoicing, correspondence or registration of tourists' departures and arrivals.

The Information systems designed for tourist bookings can operate with both individual tourists and travel agencies. They combine the actual booking and sales services with the information services.

The systems are modularised and allow interconnection of ticketing, outgoing, incoming and internal departments, etc. from the tourist reception structures or from the agencies with the financial-accounting departments and their management. Among other things, they allow the sending and receiving of data to and from global distribution systems such as Worldspan and Amadeus.

The tourism portal can be seen as a business community infrastructure that provides a transparent environment for tourism business development. The Tourism Portal brings together the parties involved in tourism activities, namely travel service providers, travel agencies and, last but not least, consumers of tourist goods and services in a virtual space on the World Wide Web. Participants play their roles in full transparency through Internet-specific tools.

Travel portals offer more and more diversified services: tourists not only can book an online stay but also will receive all the information via e-mail and will pay everything online via credit card.

The intelligent agents play an important role in e-business in general and in electronic tourism in particular, providing Internet-based assistance, helping potential tourism consumers to compare tourist offers or automatically informing users about recent events. Through intranet, Internet, or extranet networks, they assist in locating and filtering data from various databases, paying close attention to details before retrieving the most conclusive data.

Among the most well-known intelligent agents are browsers, search engines and RSS readers.

\section{Key-points for online tourism}

The tourism sector leads the wider European economy in terms of the use of online platforms. [The Impact of Online Content on European Tourism, 2017]

The majority of the European population has reliable access to the Internet and online platforms are being used with much greater frequency in all aspects of daily life. [The Impact of Online Content on European Tourism, 2017] 


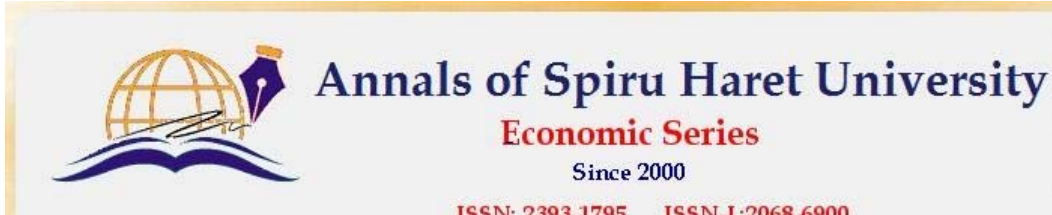

ISSN: 2393-1795 ISSN-I-2068-6900

Issue 1/2018

Mobile Internet use is also growing. Across the EU, 6 out of 10 mobile phone users now have access to the Internet from their smartphone. Mobile use is changing the way people use the Internet for booking and researching travel, including while they are already on trips. [The Impact of Online Content on European Tourism, 2017]

Social media prevalence among the younger generation in all EU countries suggests that the influence of online content will continue to grow. [The Impact of Online Content on European Tourism, 2017]

Tourism businesses in Europe need to be aware of source market demand and use online platforms to reach their audience effectively. [The Impact of Online Content on European Tourism, 2017]

Constraints on online sales remain evident, including lingering mistrust of online platforms in certain markets, as well as further limits from some aversion to credit card use. [The Impact of Online Content on European Tourism, 2017]

Online sales and use of established and trusted sales platforms can help smaller tourism businesses access larger source markets. [The Impact of Online Content on European Tourism, 2017]

Businesses, which just match the ability to sell online to local preferences, will miss sales to potential travellers from foreign markets that may be more comfortable buying online. [The Impact of Online Content on European Tourism, 2017]

On worldwide, e-commerce in tourism is defined as the sale-purchase and marketing of products and services through an electronic system such as the Internet. It involves electronic data transfer, distribution management, e-marketing, online marketing, online transactions, electronic data exchange, automated inventory management systems, and automatic data collection.

The online tourism relies primarily on information distribution, but the main purpose is direct sales, eliminating physical and time barriers by using e-commerce technologies. For example, the hotel industry can talk about booking through viable booking systems, as well as real-time booking systems. Direct sales potential is a big one, based on a number of advantages for tourism providers, such as automation, removal of the travel agent's commission, reduction of Internet reservation costs over traditional methods, and increase of bookings due to new methods to access the Web.

\section{Conclusions}

In conclusion, forecasts for the development of online tourism are very optimistic, given that more and more people have access to the Internet. Even though the market is dominated by classic agencies, with the development of own 


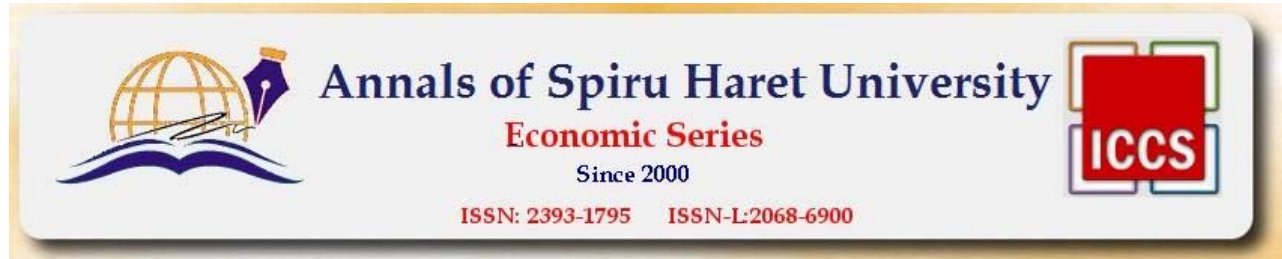

Issue 1/2018

sites, more and more agencies have moved from the offline sale system to selling via the Internet, investing more and more in this direction, or promoting tourist packages through travel portals - which can guarantee their access to a growing number of clients and, therefore, long-term success.

The advantages of the online tourism are:

First of all, the major advantage is transparency! The details, facilities, prices, location, and images, all must correspond to reality, because the consequences can be disastrous otherwise!

The second advantage is the collaboration: social networks make wonders for the hotel industry, and even for tourism in general. The possibilities offered by these means of communication are unlimited. Imagine connections between millions of people and how easy it is to find out what you can visit in a city, where you can eat the best and all sorts of other little tricks.

Another advantage is speed. A simple search on Google and in a few seconds we find detailed information about all the places we dream to see one day.

We also need to mention the stage underway in the virtual world: predictability. All online travel platforms are heading towards this, which, through intelligent systems, offers recommendations that suit us perfectly.

With a smartphone, PC or a laptop and an Internet connection we can analyze an unlimited number of offers, compare or read other people's opinions. The truth is that it is absolutely wonderful to have so many options, but it can be very difficult to decide. From my point of view, this is the most important advantage of the online tourism environment: interconnecting profiles from social networks with previous reservations and with others factors to provide you with relevant results.

Those who have the most to win are tourists, who can plan their holidays much faster and more comfortably, and the tourism industry, which draws closer to western standards and to the much-anticipated and well-earned growth.

\section{References}

1. Direct Booking (2018), accessed February 7, 2018, https://www.directbooking.ro

2. "The Impact of Online Content on European Tourism (2013)", Oxford Economics, accessed February 7, 2018, http://www.oxfordeconomics.com/my-oxford/projects/ 246666

3. "The Impact of Online Content on European Tourism (2017)", Oxford Economics, accessed February 7, 2018, http://www.oxfordeconomics.com/recent-releases/theimpact-of-online-content-on-european-tourism 